\title{
Myocardial injury occurs earlier than myocardial inflammation in acute experimental viral myocarditis
}

\author{
Byung-Kwan Lim ${ }^{1}$, Jae-Ok Shin ${ }^{1}$, \\ Seong-Choon Choe ${ }^{2}$, Si-Wan Choi ${ }^{3}$, \\ Jin-Ok Jeong ${ }^{3}$, In-Whan Seong ${ }^{3}$, \\ Duk-Kyung $\mathrm{Kim}^{1}$ and Eun-Seok Jeon ${ }^{1,4}$ \\ ${ }^{1}$ Department of Medicine \\ Sungkyunkwan University School of Medicine \\ Cardiac and Vascular Center, Samsung Medical Center \\ Seoul 135-710, Korea \\ ${ }^{2}$ Department of Scientific Affairs \\ Sanofi-Synthelabo Korea, Seoul, Korea \\ ${ }^{3}$ Department of Internal Medicine \\ Chungnam National University Hospital \\ Daejeon, Korea \\ ${ }^{4}$ Coressponding author: Tel, 82-2-3410-3448; \\ Fax, 82-2-3410-3849; E-mail, esjeon@smc.samsung.co.kr
}

Accepted 1 February 2005

Abbreviations: CK-MB, creatine kinase MB isoform; CVB3, coxsackievirus group B3; CVB3-H3, myocarditic H3 strain of CVB3; CVB3-10A1, less myocarditic variant of CVB3-H3; PFU, plaque forming unit; m.o.i, multiplicity of infection; cTnT, cardiac isoforms of troponin $\mathrm{T}$; EMB, endomyocardial biopsy

\footnotetext{
Abstract

Endomyocardial biopsy often fails to show myocardial inflammation for patients with clinically suspected myocarditis. The serum isoforms of troponin $T$ (cTnT) level is a very sensitive marker of myocardial injury and it is elevated even in the absence of myocardial inflammation. We investigated the correlations for myocardial injury, virus titers and inflammation in acute viral infection. Using the murine coxsackievirus group B3 (CVB3) myocarditis model, the histopathologic findings and virus titers in mouse hearts were compared with the serum CTnT levels measured by ELISA at various time points. Viable virus titers in the hearts peaked at 3 days after infection $\quad\left(8.22 \pm 0.13 \quad \log _{10}\right.$ PFU/100 $\mathrm{mg}$ of heart); they decreased at day 7 and no viable virus was detected from day 14. Myocardial inflammation was minimal at day 3 , peaked at day 7 and markedly decreased at day 14 . The individual serum $\mathrm{TnT}$ levels were significantly
}

increased at day $3(7.37 \pm 1.46 \mathrm{ng} / \mathrm{ml})$, persisted to day $7(0.73 \pm 0.08 \mathrm{ng} / \mathrm{ml})$, and normalized at day 14. Serum cTnT levels were correlatable with virus titers in the heart $(r=0.744, P<0.01)$, but the serum cTnT levels were not correlated with the degrees of inflammation. Using the less myocarditic strain of CVB3, similar relationships were observed between the changes for the serum cTnT levels and the heart virus titers. During the course of viral infection, myocardial injury precedes the pathologic evidence of inflammation, and the elevated cTnT levels provide evidence of myocardial injury even in the absence of any histologic findings of myocarditis.

Keywords: inflammation; myocardial injury; troponin; viral myocarditis

\section{Introduction}

Viral myocarditis is the result of a viral infection that produces myocardial necrosis, and this triggers an immune response for eliminating the viral agent (Kawai et al., 1999; Knowlton et al., 1999; Feldman et al., 2000). The definitive diagnosis of myocarditis has to be established by the demonstration of myocytolysis and the lymphocytic infiltrates in the endomyocardial biopsy (EMB) specimens (Aretz et al., 1987). However, EMB has confirmed the diagnosis of myocarditis in only about $10-25 \%$ of the patients in whom this disease was clinically suspected (Fowles et al., 1984; Parrillo et al., 1984; Mason et al., 1995), and repeated EMBs are not warranted in some clinical situations. The timing of EMB is very important because it is known that the clinical and histological features of myocarditis do not always coincide together. During the course of myocarditis, the laboratory markers of myocardial cell damage, such as creatine kinase (CK) and creatine kinase MB isoform (CK-MB) levels are often within the normal range (Lauer et al., 1997; Smith et al., 1997).

Cardiac isoforms of troponin T or I (cTnT, cTnl) are only expressed in cardiac muscle and their serum levels have been proved to be more sensitive than the CK levels to detect myocardial injury in many clinical situations including unstable angina pectoris (Hamm et al., 1992; Bachmaier et al., 1995; Lauer et al., 1997; Smith et al., 1997). In clinically suspected myocarditis, the serum TnT level is elevated even in the absence of any histologic signs of myocarditis (Lauer et al., 1997; Smith et al., 1997). In autoim- 
mune murine myocarditis, cardiac troponin is a more sensitive marker than creatine kinase $M B$ isoform (CK-MB), and an elevated troponin level clearly indicates myocarditis (Bachmaier et al., 1995; Smith et al., 1997).

To investigate the correlations among myocardial injury, virus titers and inflammation during the course of acute viral infection, we measured the serum cTnT levels and the viral titers, and examined the histologic findings in mouse hearts at various time points during the experimental course of a murine coxsackieviral B3 (CVB3) myocarditis.

\section{Materials and Methods}

This investigation conforms to the Guide for the Care and Use of Laboratory Animals published by the US National Institutes of Health (NIH Publication No. 85-23 revised 1996). All the procedures were reviewed and approved by the Animal Care and Use Committee at Samsung Medical Center, Seoul, Korea.

\section{Murine viral myocarditis}

The myocarditis studies were performed on inbred female $\mathrm{Balb} / \mathrm{C}$ mice that were all approximately eightweek old and twenty grams in weight. The animals were maintained at Korean Research Institute of Chemical Technology, and the original strains were obtained from Harlan, Indianapolis, Indiana, USA. The two CVB3 viruses were derived from the infectious cDNA copies of a myocarditic H3 strain of CVB3 (H3 variant of the Woodruff strain, CVB3-H3), and a less myocarditic variant of CVB3-H3 (CVB3-10A1). The neutralizing monoclonal antibody (10A1) escape mutant (CVB3-10A1) is able to infect the myocardium, but the inflammatory response of the host to this virus is severely attenuated compared that of CVB3-H3 virus (Van Houten et al., 1991; Knowlton et al., 1996). The viruses were titered using the plaque-forming unit (PFU) assay for HeLa cells (Knowlton et al., 1996). In experiment 1 , the eight week-old female Balb/C mice were infected by an intraperitoneal (ip) injection with $10^{4} \mathrm{PFU}$ of CVB3-H3 $(n=40)$. The mice were sacrificed by euthanasia, and the whole blood and hearts were collected aseptically at day $3(n=10)$, day $7(n=10)$ and day 14 after the infection $(n=6)$. Since the survival rate of CVB3 infected mice at day 14 was less than $30 \%$, the dead mice during the experiments were excluded from the analysis of the pathology, and the cTnT assays. Sera were isolated by centrifugation and stored at $-70^{\circ} \mathrm{C}$ until use in the cTnT assays. To determine whether the virus replication in the hearts can cause myocardial damage without inflammation, the mice were infected with CVB3-H3 $\left(10^{4}\right.$ PFU ip, $\left.n=20\right)$, or they were infected with the less myocarditic CVB3-10A1 virus $\left(10^{4}\right.$ PFU ip, $n=15)$ in experiments 2 . These mice were sacrificed by euthanasia, and whole blood and hearts were aseptically collected in a serial fashion as described earlier ( $n=5$ for CVB3-H3, $n=4$ for CVB3-10A1 at each day), and the dead mice during the experiments were also excluded from the analysis of the pathology and the cTnT assay.

\section{Organ virus titer and histologic analysis}

The base parts of the hearts were weighed and homogenized in Dulbecco's Modified Eagle's Medium (DMEM) containing $4 \%$ fetal calf serum (FCS). The cellular debris was removed by centrifugation at 300 $\mathrm{g}$ for $10 \mathrm{~min}$. The viral titers in the supernatants were determined by PFU assay using HeLa cells. The apical parts of the hearts were fixed in $10 \%$ formalin, embedded in paraffin and stained with hematoxylineosin and Masson's trichrome. The prepared sections were graded for cardiac inflammation by two "blinded" researchers using a scale of 0 to 4 in which 0 represented no myocarditis, 1 represented 1-10 lesions of focal myocardial inflammation in high power fields $(\times 400), 2$ represented 11 to 20 lesions, 3 represented 21 to 40 lesions, and 4 represented widespread and confluent inflammation (Knowlton et al., 1996).

\section{ELISA testing for the serum troponin $T$ levels}

The levels of serum TnT were measured by the Sandwich ELISA method using a Elecsys TnT sTAT kit (Roche, Mannheim, Germany). This kit had been produced for the detection of human CTnT, the reliability of cTnT ELISA test has been proven and the monoclonal antibody in this kit has displayed a similar reactivity pattern in mice and humans. (Katus et al., 1992) The collected mouse sera were directly used for the TnT assays, and the serial dilutions of human TnT were employed as a standard.

\section{Evans blue dye staining of the hearts}

To identify the myocardial injury during active CVB3 replication in the heart, $100 \mu$ l of Evans Blue dye $(10 \mathrm{mg} / \mathrm{ml}$ in PBS) was injected intraperitoneally 12 $\mathrm{h}$ before harvesting hearts, as was described in previous reports (Straub et al., 1997; Bandorff et al., 1999), at day 3 and day 7 after both CVB3 infections. Since CVB3 viral protease $2 A$ cleaves the dystrophin when viruses proliferate in the infected myocytes, Evans blue dye can stain those infected myocytes where the cell membrane have been damaged (Bandorff et al., 1999). The harvested hearts were embedded in OCT Tissue Tek and snap-frozen in liquid nitrogen. The unfixed $6 \mathrm{~mm}$ cryosections were then observed under fluorescent microscopy.

\section{Statistics}

Data are presented as means \pm SEM. Statistic analysis was performed using SPSS 10.0 for Windows (SPSS Inc, Chicago, IL). Student's $t$-test was used for the analysis of numeric parameters. The correlations 
between the serum TnT levels and myocarditis score, and between the serum TnT levels and the virus titers in the hearts were analyzed by Pearson correlation analysis. Differences were considered significant at $P$ $<0.05$.

\section{Results}

\section{Heart Virus Titers and Histopathology of the CVB3-H3 infected mice}

The viable CVB3-H3 virus titers in the hearts were found to peaked at day $3(n=10)$ after the infection $\left(8.22 \pm 0.13 \log _{10} \mathrm{PFU} / 100 \mathrm{mg}\right.$ of heart), and they had decreased at day $7\left(n=10,3.62 \pm 0.33 \log _{10}\right.$ PFU/100 mg of heart). No viable virus was detectable beyond day $14(n=6)$ after the infection (Table 1$)$. Infiltration of inflammatory cells was also detected from day 3 days, peaked at day 7 , and markedly decreased at day 14 post infection (Table 1). Myocardial necrosis, fibrosis and calcification were detectable from day 7 (Figure 2B) and diffuse fibrosis and thin left ventrical (LV) walls were observed, and
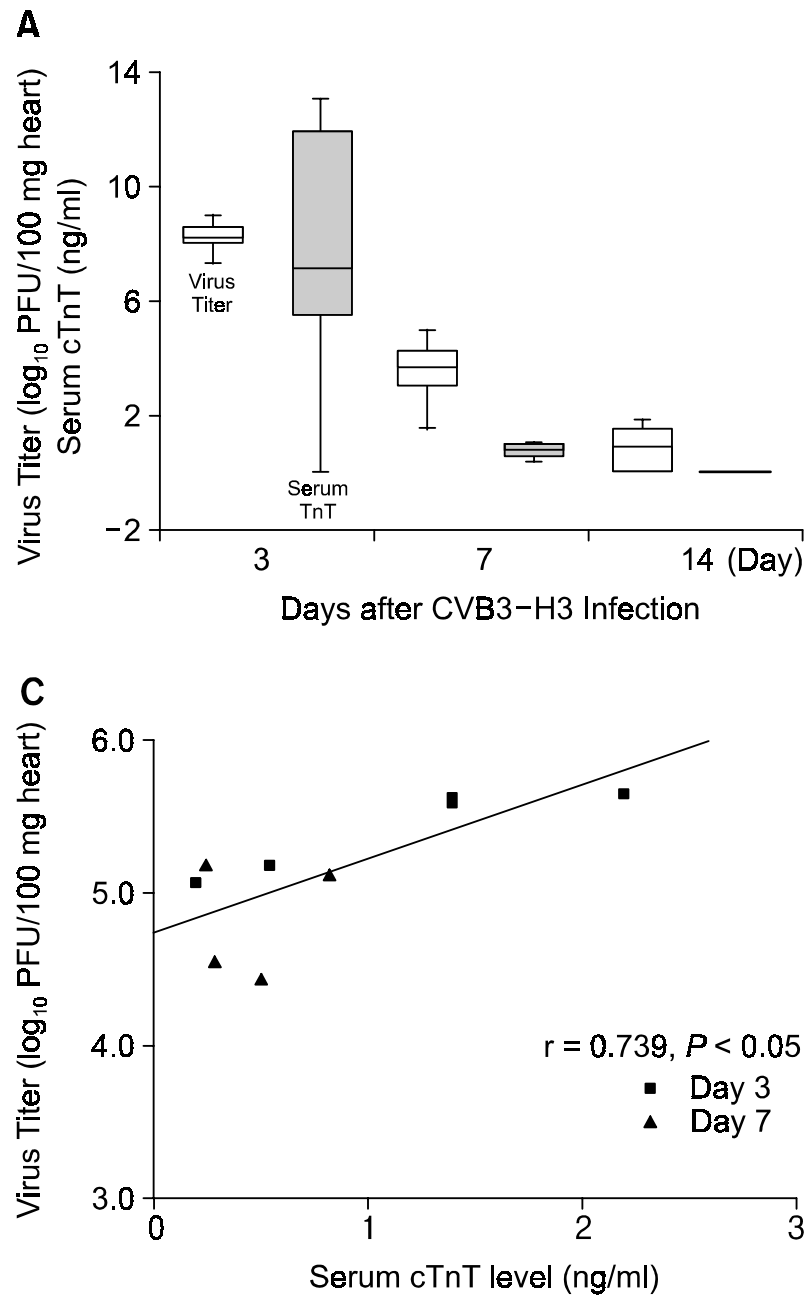

the inflammatory cell infiltrations were markedly decreased at 14 days after the CVB3-H3 infection

Table 1. Myocarditis score, heart virus titer and the serum cTnT levels in Balb/c mice infected with CVB3-H3 virus at various time points.

\begin{tabular}{|c|c|c|c|}
\hline & $\begin{array}{l}\text { Day } 3 \\
(n=10)\end{array}$ & $\begin{array}{l}\text { Day } 7 \\
(n=10)\end{array}$ & $\begin{array}{l}\text { Day } 14 \\
(n=6)\end{array}$ \\
\hline $\begin{array}{l}\text { Myocarditis } \\
\text { score }\end{array}$ & $1.50 \pm 0.17$ & $3.10 \pm 0.31^{*}$ & $1.33 \pm 0.33^{\dagger}$ \\
\hline $\begin{array}{l}\text { Heart virus } \\
\text { titer }\end{array}$ & $8.22 \pm 0.13$ & $3.62 \pm 0.33^{*}$ & $0.88 \pm 0.31{ }^{*}$ \\
\hline $\begin{array}{l}\left(\log _{10} \mathrm{PFU} /\right. \\
100 \mathrm{mg} \text { heart) } \\
\text { Serum TnT } \\
\text { level }(\mathrm{ng} / \mathrm{ml})\end{array}$ & $7.37 \pm 1.46$ & $0.73 \pm 0.08^{*}$ & $0.04 \pm 0.01^{*+}$ \\
\hline
\end{tabular}

Data are presented as means \pm SEM.

Myocarditis scoring was done as described in materials and methods. ${ }^{*} P<0.05$ compared with Day $3,{ }^{\dagger} P<0.05$ compared with Day 7 .

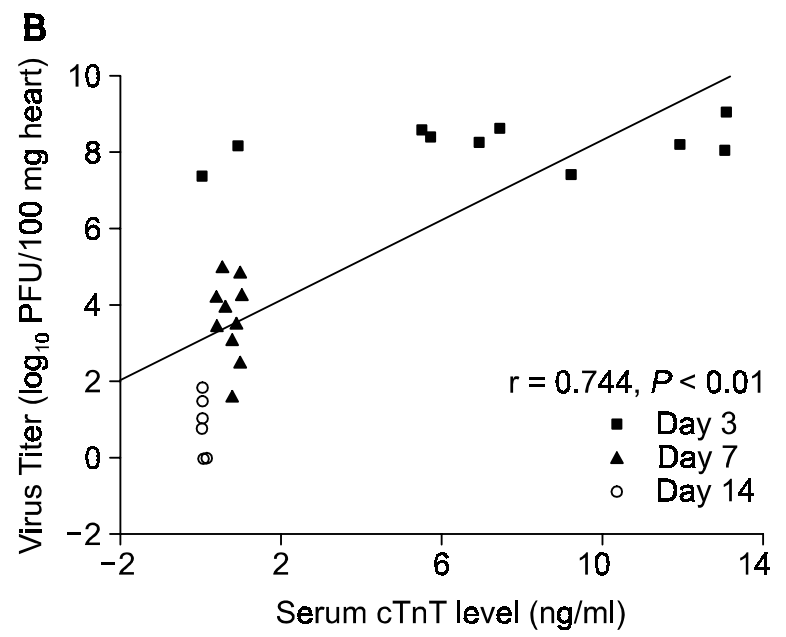

Figure 1. (A) Serum CTnT levels and viable virus titers in the heart at various time points after CVB3-H3 infection. The boxplots display the median, interquartile ranges, maximum and minimum of virus titers (left box at each day) and serum CTnT levels (right box at each day). ( $n=10$ at day 3 and $7, n=6$ at day 14). (B) Correlations between serum CTnT levels and viable viral titers in the hearts infected with CVB3-H3. Serum CTnT levels were correlated with viable virus titers in the hearts $(r=0.744, P<0.01)$. (C) Correlations between serum CTnT levels and viable viral titers in the hearts infected with CVB3-10A1. Serum CTnT levels were correlated with viable virus titers in the hearts at days 3 and 7 after the virus infection $(r=0.739, P$ $<0.05)$. 
(Figure 2C, 2F and 2I).

\section{Serum cardiac troponin $\mathrm{T}$ levels, heart virus titers and the histology}

The serum cTnT levels were changed in a time-dependent manner in this murine CVB3-H3 myocarditis model (Table 1, Figure 1A). The individual serum TnT level was significantly increased at day 3 (7.37 \pm $1.46 \mathrm{ng} / \mathrm{ml}$ ) in 9 of 10 mice, and this persisted to day $7(0.73 \pm 0.08 \mathrm{ng} / \mathrm{ml}) ;$ the TnT level was then normalized at day $14 \quad(0.04 \pm 0.01 \mathrm{ng} / \mathrm{ml})$. Serum cTnT levels peaked at day 3 when the virus was maximally replicated in the heart, and at this time, little inflammatory cell infiltration was noted. At day 7, when the inflammation was peaked, the serum cTnT levels were still elevated, but they were significantly lower than those of day 3 . At day 14, the major pathologic changes in the heart were fibrosis and calcification, there was LV dilatation with minimal inflammation, and the serum cTnT level was decreased to the normal range (Table 1, Figure $1 \mathrm{~A}$ ). The serum cTnT levels correlated with the virus titers in the hearts infected with CVB3-H3 as well as in the hearts infected with CVB3-10A1 (Figure 1B and 1C $r=0.744$ and $r=0.739, P<0.01$, respectively), but the serum cTnT levels were not correlated with the degree of inflammations in the CVB3-H3 infected hearts $(r=-0.251, P>0.05$, data not shown). These findings suggest that during this active viral replicating period in the hearts, the damaged myocardial cells released more cTnT than they did during the inflammatory period.

\section{Comparisons of myocardial injury and virus titer between the two viruses}

In the CVB3-10A1 infected mice, even though the inflammatory cell infiltrates in the hearts were scanty at days 3 and 7 , the individual serum cTnT levels significantly increased $(n=4,1.14 \pm 0.35 \mathrm{ng} / \mathrm{ml})$ in all the mice at day 3 , and decreased $(n=4,0.47 \pm$ $0.13 \mathrm{ng} / \mathrm{ml}$ ) at day 7 (Table 2). In the frozen section of hearts, there were more myocytes stained by the Evans blue dye in the day 7 hearts than there were in the day 3 hearts for both viruses. More myocytes were stained by Evans blue dye in the CVB3-H3 infected hearts at each day than there were in those CVB3-10A1 infected hearts (Figure 3, B through E).

In summary, the hearts infected with CVB3-10A1 virus had lower viral titers than those hearts infected with CVB3-H3 virus, and there was less myocardial injury as defined by the serum cTnT levels and Evans blue dye uptake. However, the relationships between the viral titers and serum cTnT levels were similar for both virus infections (Table 2, Figure $1 \mathrm{~B}$ and $1 \mathrm{C}$ ). These findings suggested that the injured myocytes during active proliferation phase after infection released more cTnT than they did during the phase of the inflammatory cell infiltrations.

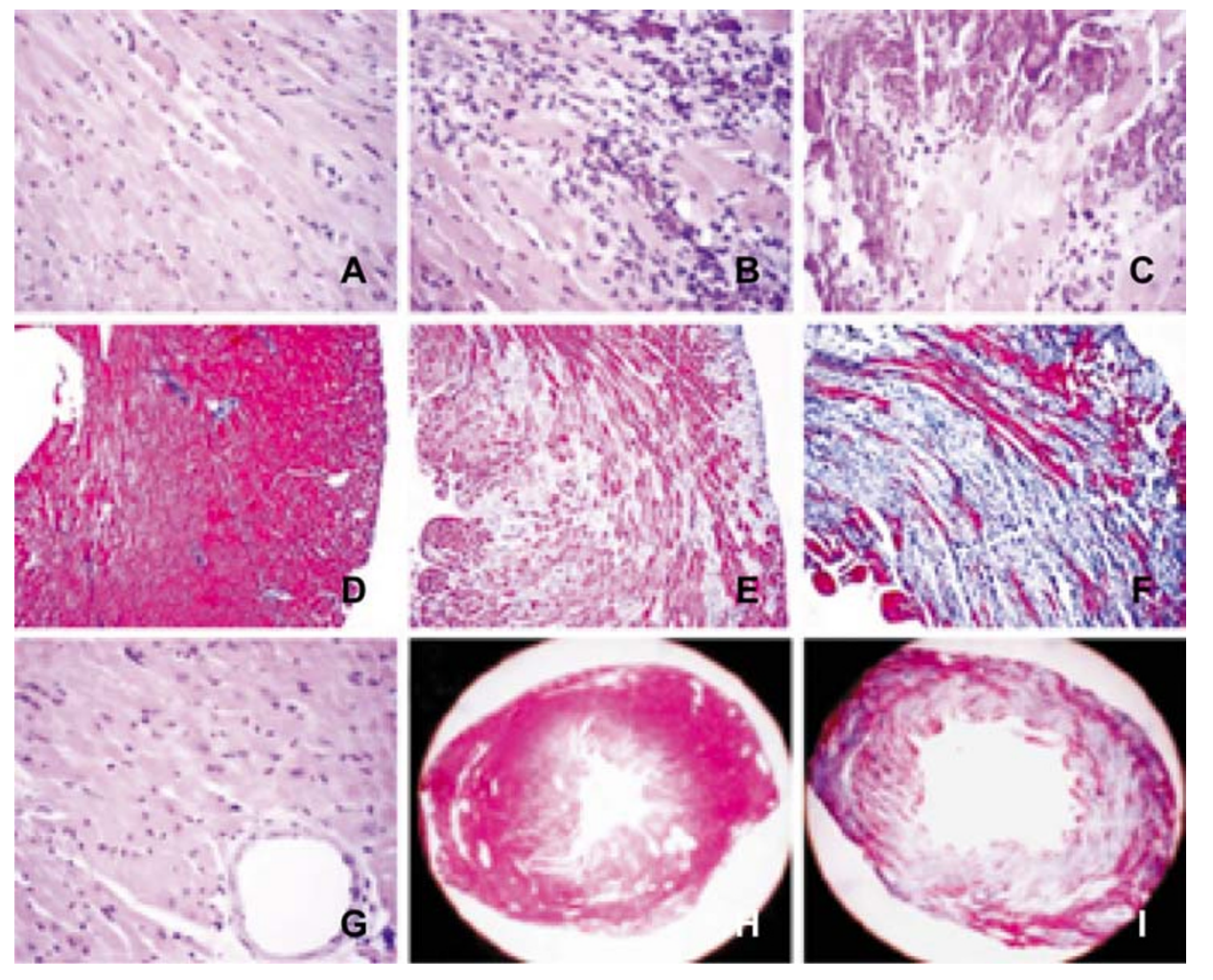

Figure 2. Histopatholgic findings of the mice hearts infected with CVB3$\mathrm{H} 3$ virus. In the day 3 hearts after virus infection, the inflammatory cell infiltrates (A) and the fibrotic changes (D) were scanty. In day 7 hearts, massive and diffuse inflammations (B) and moderate fibrosis (E) were observed. In day 14 hearts, the inflammatory cell infiltrates $(C)$ were decreased, and massive fibrosis and severe calcification were observed $(F)$, and the left ventricle (LV) was dilated and the LV wall was very thin (I). (G, H; normal control heart, A through C, G; hematoxylin-eosin stain, $D$ through $\mathrm{F}, \mathrm{H}, \mathrm{I}$; Masson-trichrome staining). (magnification; $A$ through $C$ and $G$, $\times 400$; $D$ through $F, \times 100 ; H$ and I, $\times 10)$. 

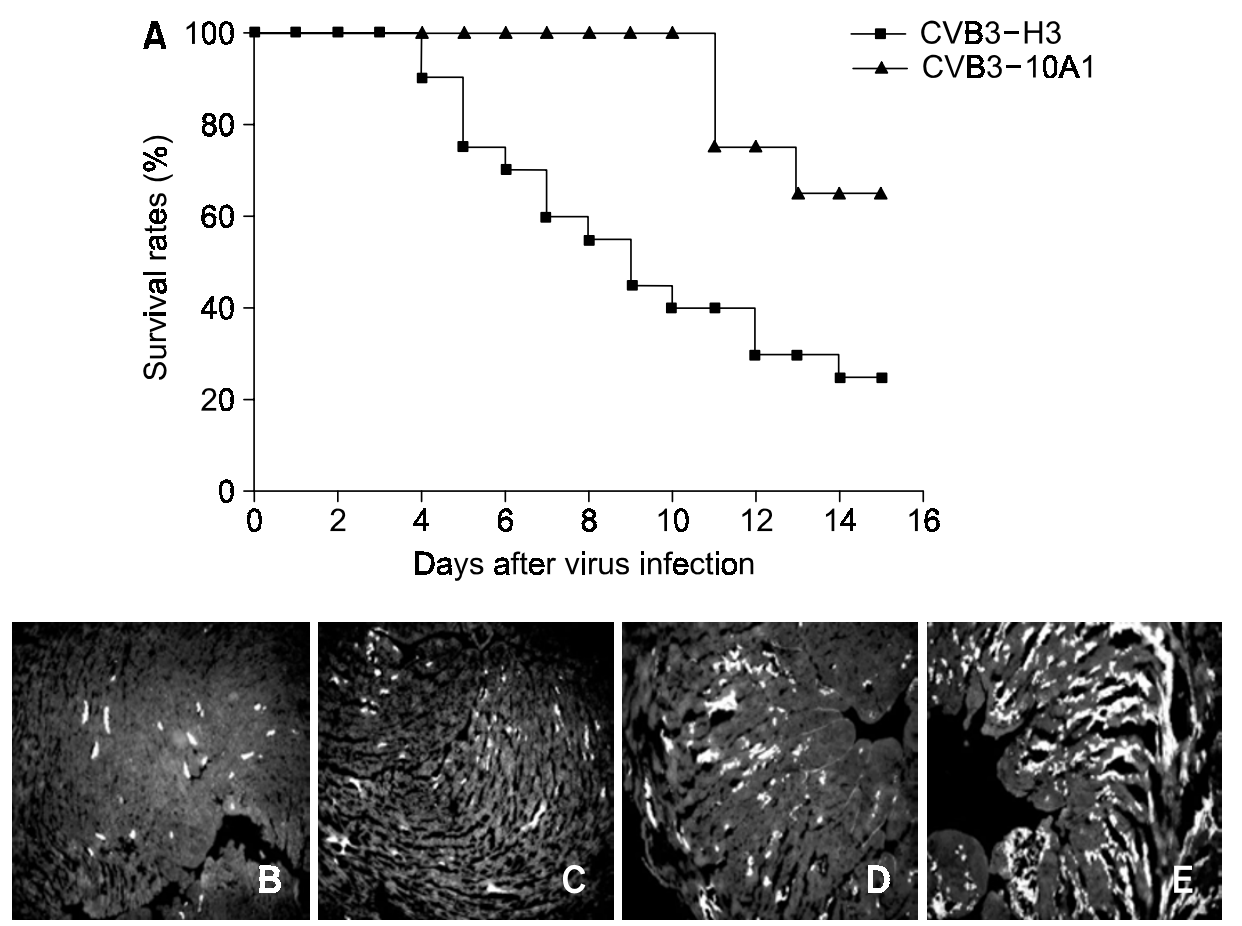

Figure 3. Survival rates and fluorescent microscopic findings of the mice infected with CVB3-H3 and CVB3-10A1 viruses. The survival rates of the mice infected with CVB3-10Al virus were higher than those mice with CVB3-H3 infection (A). Evans blue dye stained less myocytes in day 3 hearts ( $B$ and C) than those myocytes that were stained in day 7 hearts ( $D$ and $E$ ) for both viruses. Evans blue dye stained more myocytes in CVB3H3 infected hearts (C; day 3, E; day 7), than those myocytes that were stained in CVB3-10A1 infected hearts (B; day $3, D$; day 7 ) on each time point. (magnification; $B$ through $E, \times 100$ ).

Table 2. Comparisons of heart virus titers and serum CTnT levels in Balb/c mice infected with CVB3-H3 and CVB3-10A1 viruses at various time points.

\begin{tabular}{llll}
\hline & & $\begin{array}{c}\text { Day 3 } \\
(n=5)\end{array}$ & $\begin{array}{l}\text { Day 7 } \\
(n=4)\end{array}$ \\
\hline $\begin{array}{l}\text { Heart virus } \\
\text { titer (Log } 10\end{array}$ & CVB3-H3 & $7.60 \pm 0.15$ & $6.47 \pm 0.32^{+}$ \\
PFU/100 mg & CVB3-10A1 & $5.42 \pm 0.12^{*}$ & $5.16 \pm 0.49^{*^{+}}$ \\
heart) & & & \\
$\begin{array}{l}\text { Serum TnT } \\
\text { level (ng/ml) }\end{array}$ & CVB3-H3 & $3.74 \pm 0.84$ & $2.07 \pm 0.64^{+}$ \\
\hline
\end{tabular}

Data presented as means \pm SEM.

Myocarditis scoring was done as described in materials and methods. ${ }^{*} P<0.05$ compared with CVB3-H3, ${ }^{+} P<0.05$ compared with Day 3.

\section{Discussion}

The present study demonstrates that the serum cTnT levels can potentially provide the hard evidence of myocardial injury during the active proliferative phase after a virus infection, and the serum cTnT levels are well correlated with viable heart virus titers, but they are not correlated with the degree of cardiac inflammation.

Coxsackie viruses are known to infect the cardiac myocytes of both humans and mice. A plaque-purified, highly myocarditic variant of CVB3, H3, was previous isolated by one passage of CVB3 virus from the heart of an infected mouse. This plaque-purified variant is highly myocarditic in Balb/C mice (Van Houten et al., 1991). The less myocarditic, antibody (10A1) escape mutant of CVB3-H3 virus (CVB3-10A1) is able to infect the myocardium, but its inflammatory response is much attenuated when compared to that of the CVB3-H3 virus (Van Houten et al., 1991; Knowlton et al., 1996).

In the murine model of acute viral myocarditis, substantial myocyte damage occurred a few days after viral infection, whereas the later phase of the disease was characterized by diffuse mononuclear cell infiltrates and fibrosis (Kawai et al., 1999 for review; Feldman et al., 2000). In our present study, we used both strains of the $\mathrm{H} 3$ variants to identify whether myocardial injury occurred without inflammation and whether this was correlated with the virus titers in the hearts. The virus titers in the hearts infected with both viruses peaked at 3 days after virus infection, the titers decreased at day 7 , and no viable viruses were detected after day 14 . When mice were infected with CVB3-H3, the most severe myocarditis with inflammatory cell infiltrate developed at day 7 , and severe LV dilatation with fibrosis and calcification was observed at day 14 when the inflammatory cell infiltrates were scanty. In the CVB3-10A1 variant infected mice, the myocardial inflammation and the virus titers in the hearts were much less than those observed for CVB3-H3 infected mice (Table 2).

Although enteroviruses are known to be the most common agents of myocarditis, there are still some discrepancies for the association of enterovirus and myocardial disease, and this is partially due to lack of data for the detection of virus antigen or viral 
culture in the tissue (Li et al., 2000; McCarthy et al., 2000; Seong et al., 2001). Moreover, the time window for the detection of inflammation after a virus infection, based on infectious-immune hypothesis (Kawai et al., 1999; Feldman et al., 2000; Jung et al., 2003), remains to be defined. The definitive diagnosis of myocarditis has to be established by the demonstration of myocytolysis and the lymphocytic infiltrates in the endomyocardial biopsy specimens (Fowles et al., 1984; Aretz et al., 1987). However, possibly because of a sampling error, the lymphocytic infiltrates may have escaped histologic and immunohistologic detection in those patients (Parrillo et al., 1984; Mason et al., 1995; Lauer et al., 1997; Smith et al., 1997; Jung et al., 2004). In the Myocarditis Treatment Trial study (Mason et al., 1995), acute myocarditis was histologically diagnosed only in $10 \%$ of the patients with clinically suspected myocarditis. Lauer et al. showed that the cTnT level was elevated in 28 of 80 patients with clinically suspected myocarditis. In patients with elevated cTnT levels, however, $82.1 \%$ (23 out of 28 patients) did not have the histologic findings to support the diagnosis of myocarditis, and this suggested that myocardial cell damage may be present even in the absence any histologic signs of myocarditis. For the patients with biopsy-proven myocarditis in the Myocarditis Treatment Trial, the cTnl levels were elevated in $18(34 \%)$ of 53 patients with myocarditis and in only $4(11 \%)$ of 35 patients without myocarditis. The elevations of the cTnl levels in patients with myocarditis were significantly correlated with heart failure symptoms, especially in patients with less than one-month duration of symptoms, suggesting that the majority of myocardial necrosis occurred earlier (Smith et al., 1997).

In the present study, the individual serum cTnT levels were significantly elevated $(>0.5 \mathrm{ng} / \mathrm{ml})$ on day 3 for 9 of 10 mice, and on day 7 for 8 of 10 mice. On day 14, the cTnT levels were below 0.1 $\mathrm{ng} / \mathrm{ml}$ for 6 of 6 mice. The serum cTnT levels were highest at day 3 when the virus was actively replicating in the heart and the viral titers had peaked. For the histologic findings, the inflammatory cells infiltrates were scanty and there was no fibrosis at all at day 3. At day 7, despite the severe myocardial inflammations observed in the heart, the viable virus titers and serum cTnT levels were lower than those of day 3. For the CVB3-10A1 infected mice, the serum cTnT levels were also significantly elevated on day 3 in all 5 mice, and on day 7 the levels were decreased to the nearly normal range. The viable virus titers in the hearts were significantly correlated with the serum cTnT levels for both viruses, but the titers were not correlated with the degree of myocarditis found in the CVB3-H3 infected hearts. This discrepancy between inflammation and myocardial injury demonstrated that during the acute viral myocarditis, the serum cTnT level was an earlier marker of myocardial injury after virus infection than was the histologic findings of inflammation. In addition, the infected myocytes released cTnT much earlier than the occurrence of membrane damage, as was de- monstrated by the Evans blue dye staining.

It is well known that the serum cTnT level is a more sensitive marker to detect myocardial injury than creatinine phosphokinase (Bachmaier et al., 1995; Lauer et al., 1997; Smith et al., 1997). Therefore, we measured only the serum cTnT level with the wellestablished human cTnT ELISA method, which is suitable to detect murine cTnT in a heart-specific manner as described earlier (Katus et al., 1992; Bachmaier et al., 1995). We could not measure the serial and peak cTnT, and the consequent LV dilatation in the same animal because the hearts and serum were sampled simultaneously at the time of sacrifice. Therefore, we could not demonstrate whether the elevated serum cTnT level in the early viremic phase can predict the severity of the heart disease at a later stage.

Our study findings showed that the serum cTnT level is an earlier marker of myocardial injury after virus inflammation than the histologic findings of inflammation. Therefore, in those patients with clinically suspected viral myocarditis who are without any histologic evidence of myocardial inflammation, additional virus detection methods such as virus culture, immunohistochemistry for viral protein, and viral genome detection by polymerase chain reaction and in situ hybridization, and the repeated endomyocardial biopsy are needed to confirm the viral etiology.

\section{Acknowledgement}

This work was supported by the grant from the Korea Health 21 R\&D Project, Ministry of Health and Welfare, Republic of Korea (98-PJ1-PG2-E-0029), and by the Samsung Biomedical Research Institute grant, \#SBRI C-A2-125-2. We wish to thank Dr. Seonwoo Kim (Biostatistics Unit, Samsung Biomedical Research Institute) for the statistical reviews and comments.

\section{References}

Aretz HT, Billingham ME, Edwards WD, Factor SM, Fallon JT, Fenoglio JJ Jr, Olsen EG, Schoen FJ. Myocarditis: A histopathologic definition and classification. Am J Cardiovasc Pathol 1987;1:3-14

Bachmaier K, Mair J, Offner F, Pummerer C, Neu N. Serum cardiac troponin $\mathrm{T}$ and creatine kinase-MB elevations in murine autoimmune myocarditis. Circulation 1995;92:192732

Badorff C, Lee GH, Lamphear BJ, Martone ME, Campbell $\mathrm{KP}$, Rhoads RE, Knowlton KU. Enteroviral protease $2 \mathrm{~A}$ cleaves dystrophin: Evidence of cytoskeletal disruption in an acquired cardiomyopathy. Nat Med 1999;5:320-6

Feldman AM, McNamara D. Myocarditis. N Engl J Med 2000; 343:1388-98

Fowles RE, Mason JW. Role of cardiac biopsy in the diagnosis and management of cardiac disease. Prog Cardiovasc Dis 1984;27:153-72

Hamm CW, Ravkilde J, Gerhardt W, Jorgensen P, Peheim 
E, Ljungdahl L, Goldmann B, Katus HA. The prognostic value of serum troponin $T$ in unstable angina. $N$ Engl J Med 1992;327:146-50

Jung HW, La SJ, Kim JY, Heo SK, Kim JY, Wang S, Kim KK, Lee KM, Cho HR, Lee HW, Kwon B, Kim BS, Kwon BS. High levels of soluble herpes virus entry mediator in sera of patients with allergic and autoimmune diseases. Exp Mol Med 2003;35:501-8

Jung HW, Choi SW, Choi JI, Kwon BS. Serum concentrations of soluble 4-1BB and 4-1BB ligand correlated with the disease severity in rheumatoid arthritis. Exp Mol Med 2004; $36: 13-22$

Kawai C. From myocarditis to cardiomyopathy: Mechanism of inflammation and cell death: learning from the past for the future. Circulation 1999:99:1091-100

Katus HA, Looser S, Hallermayer K, Remppis A, Scheffold $T$, Borgya A, Essig U, Geuss U. Development and in vitro characterization of a new immunoassay of cardiac troponin T. Clin Chem 1992;38:386-93

Knowlton KU, Jeon ES, Berkley N, Wessely R, Huber SA. A mutation in the puff region of VP2 attenuates the myocarditic phenotype of an infectious cDNA of the Woodruff variant of coxsackievirus B3. J Virol 1996;70:7811-8

Knowlton KU, Badorff C. The immune system in viral myocarditis: maintaining the balance. Circ Res 1999;85:559-61

Lauer B, Niederau C, Kuhl U, Schannwell M, Pauschinger $M$, Strauer BE, Schultheiss HP. Cardiac troponin $T$ in patients with clinically suspected myocarditis. J Am Coll Cardiol 1997;30:1354-9
Li Y, Bourlet T, Andreoletti L, Mosnier JF, Peng T, Yang Y, Archard LC, Pozzetto B, Zhang H. Enteroviral capsid protein VP1 is present in myocardial tissues from some patients with myocarditis or dilated cardiomyopathy. Circulaton $2000 ; 101: 231-4$

Mason JW, O'Connell JB, Herskowitz A, Rose NR, McManus $\mathrm{BM}$, Billingham ME, Moon TE. A clinical trial of immunosuppressive therapy for myocarditis. N Engl J Med 1995; 333:269-75

McCarthy RE 3rd, Boehmer JP, Hruban RH, Hutchins GM, Kasper EK, Hare JM, Baughman KL. Long-term outcome of fulminant myocarditis as compared with acute (nonfulminant) myocarditis. N Engl J Med 2000;342:690-5

Parrillo JE, Aretz HT, Palacios I, Fallon JT, Block PC. The results of transvenous endomyocardial biopsy can frequently be used to diagnose myocardial diseases in patients with idiopathic heart failure. Circulation 1984;69:93-101

Seong IW, Choe SC, Jeon ES. Fulminant coxsackieviral myocarditis. N Engl J Med 2001;345:379

Smith SC, Laden JH, Mason JW, Jaffe AS. Elevations of cardiac troponin I associated with myocarditis. Experimental and clinical correlates. Circulation 1997:95:163-8

Straub V, Rafael JA, Chamberlain JS, Campbell KP. Animal models for muscular dystrophy show different patterns of sarcolemmal disruption. J Cell Biol 1997;139:375-85

Van Houten N, Bouchard PE, Moraska A, Huber SA Selection of an attenuated coxsackievirus B3 variant, using a monoclonal antibody reactive to myocyte antigen. J Virol $1991 ; 65: 1286-90$ 